\title{
Corticotroph Adenoma
}

National Cancer Institute

\section{Source}

National Cancer Institute. Corticotroph Adenoma. NCI Thesaurus. Code C7462.

An adenoma of the pituitary gland that produces corticotropin. The vast majority of cases are associated with Cushing disease. Clinical manifestations include truncal obesity with thin extremities, thinning of the skin, osteoporosis, and a tendency to bruise easily. Silent or hormonally non-functioning ACTH producing adenomas have also been described. They produce symptoms of a mass-related lesion. 